\title{
Film and Television Culture Industry and Urban Image Communication of Zhuhai
}

\author{
Ruihui $\operatorname{Han}^{1}$ \\ ${ }^{1}$ Humanities School, Jinan University, Zhuhai, China \\ Correspondence: Ruihui Han, Humanities School, Jinan University, Zhuhai, China. E-mail: \\ hanruihuihh@hotmail.com
}

Received: November 1, 2013 Accepted: December 6, 2013 Online Published: December 31, 2013

doi:10.5539/ass.v10n1p158 URL: http://dx.doi.org/10.5539/ass.v10n1p158

\begin{abstract}
Zhuhai is an important place where film and television works have their framing and several hundred film and television works are shot each year. However, images of Zhuhai in film and television works are not sufficiently shown. Obviously, this is a regret and even a crisis in the era when Chinese cities' competition becomes increasingly fierce. By analyzing and summarizing the relationship between film and television culture industry and urban image communication, this thesis discusses the ways in which Zhuhai uses the film and television culture industry effectively to improve its urban image and enhance urban competitiveness.
\end{abstract}

Keywords: Zhuhai, film and television culture, urban image

\section{Introduction}

As a famous tourist city in China, Zhuhai is also a place where a number of film and television works have their framing. It is no doubt that many film and television works can play a positive role in propagating urban image. Do film and television works positively accelerate urban image communication of Zhuhai or not? How can we make use of screen culture industry to propagate Zhuhai's urban image effectively? These are the content that this thesis will discuss.

\section{Review of Research Literature}

Theses related to Chinese screen culture industry and urban image communication mainly include Screen Culture and Urban Image Communication (Li \& Xue, 2006), Research on Communication of Modern Urban Image by Films (Tong \& Zhang, 2012) and Urban Image Communication of TV Plays and Competition of Culture Soft Power (Zhu \& Wang, 2010) etc. Such theses mainly discuss screen culture's beautifying effect on urban image, accumulative propagation effect, impacts on urban consumer culture and influences on urban competitiveness, and also probe into problems we should pay attention to when film and television works are used to carry out urban image communication.

Theses about the screen culture industry and specific image communication of China still involve Using Advertisements Embedded in Film and Television to Build Urban Image of Yongzhou (Liu \& Xu, 2011), Utilizing Screen Culture Actively to Accelerate Urban Image Construction and Communication of Liaoning (Li, 2012) and Analyzing the Effect of TV Series Noble Family on City Image by Image Reading Method (Wang, Li $\& \mathrm{Xu}, 2011)$. These theses specifically discuss effective cases about urban image communication by literary film and television works and analyze effects of all elements in film and television works on image communication of a certain city.

However, problems about the relationship between film and television works and urban image communication of Zhuhai have not been discussed yet.

\section{Research Design}

\subsection{Introduction to Sampling Method and Research Objects}

In this thesis, the research on the screen culture industry and urban image communication of Zhuhai is on the basis of main film and television works that have been shot in this city.

The study on film and television of Zhuhai is carried out by hierarchical, simple and random sampling. Besides, via analyzing and studying related features of components in film and television works that have been shot in 
Zhuhai, it explores researches on the relationship between film and television photography and urban image communication of Zhuhai.

In consideration of the situation that the number of film and television works shot in Zhuhai is quite large, analyzed objects of this thesis target main films that have been shot in this city in recent twenty years. Some famous film and television works that have been shot in Zhuhai in recent twenty years are primarily finished by some famous actors and well-known directors. Thus, according to this situation, this thesis divides films shot in Zhuhai into two kinds: film and television works completed by famous actors and well-known directors, and common works.

1) Film and television works that famous actors and directors take part in. These films mainly include Shaolin Soccer where Chinese film stars Stephen Chow and Vicki Zhao act the leading role, Macao 1949 whose leading actor is Ray Lui, Having An Appointment with Youth in which Alec Su and Li Yuan are leading actors, Fast Track Love where Yi Lu and Vicki Zhao act the leading role and Stepmother whose protagonists are Xiaoyi Chen and Guoli Zhang. Such films' actors are film stars so that they have wide propagation, long propagating duration and huge influence.

2) Common films shot in Zhuhai. Overall, there are many such films. Randomly, five film and television works are selected, i.e., Behind the Moon, Hero of the Sea, The Code Name Rapier, Municipal Party Secretary and Flowers of Happiness. The number of such film and television works is rather large and they take Zhuhai as shooting background. However, their popularity is not high.

Besides, according to whether film and television works attach importance to reflect people and customs of Zhuhai, we can divide them into two kinds as well. The first kind is that some film and television works center on reflecting local life-style and customs of Zhuhai. The other kind just has framing in Zhuhai, so the content of stories is related to this city.

1) Works that are shot in Zhuhai and reflect local conditions and customs and historical stories of this city. This kind of works in recent twenty years mainly includes Zhuhai Fishing Girl, Sky People, Ruilian, Between Two Cities and the televised documentary One Day at Yuhu Lake. Content of these films mainly focuses on local conditions and customs in Zhuhai to form narration about this city.

2) Films that only have their framing in Zhuhai but do not tell stories about local conditions and customs of Zhuhai involve Large Dragon Vein, Proof of the Man, Promise of Fortune, Heart-Stolen Inquiry, Speed Angels, Heroes Have No Rue and Sino-Japanese Sea Warfare etc. Most of these films have their framing in Zhuhai and local people of this city can see familiar scenes in this kind of works.

The foregoing classification constitutes total samples of the research in this thesis.

\subsection{Analysis of Research Objects' Attributes and Elements}

For film and television works, there are analysis elements including theme, structure, character, scene, different scenes, space, camera, light, tone and conversation. Elements having close relations with urban image communication mainly involve theme, character and scene. Therefore, this thesis deems that investigations about whether film and television works contribute to urban image communication of Zhuhai should mainly start from the following aspects.

Firstly, theme. In general, themes are soul and essence of film and televison works. It can be said that whether a film's theme centers on reflecting urban image of Zhuhai is the most important factor by which the film has propagating effects on the urban image of the city Zhuhai.

Secondly, character. In other words, it involves whether characters in film and television works are Zhuhai people. This kind of characters can be local historical people of Zhuhai or immigrants.

Thirdly, scene. Specifically, it refers to whether scenes in film and television works can make people have immediate association with Zhuhai or whether such works can propagate urban image of Zhuhai positively and effectively.

\section{Analysis of Research Results}

1) Themes, characters and scenes reflected by works which are shot in Zhuhai and famous actors and directors take part in cannot make people have immediate association with Zhuhai. Take Shaolin Soccer whose leading actor is Stephen Chow for example. First of all, its theme does not have relationship with urban image of Zhuhai. Secondly, its characters also have no relation with history and reality of Zhuhai. In addition, as for its scenes, the scenes in several important plots appearing in the film only include the gate to Xiangshan Park of Zhuhai and the football field of Zhuhai Sports Center although the film has its framing in the city. However, these scenes cannot 
reflect or imply positive urban image of Zhuhai. In this film, characters and plots are the most important elements, while scenes appear as affiliated elements. Thus, urban image of the framing place Zhuhai is not reflected effectively.

2) Take common film and television works shot in Zhuhai as another example. It is more difficult for people to associate themes, scenes and characters of many works with Zhuhai, such as Municipal Party Secretary, Flowers of Happiness and Sino-Japanese Sea Warfare. Firstly, themes and characters of this kind of works have no relationship with Zhuhai. As for scenes, although there are a great many of beautiful sceneries and buildings of Zhuhai in such works and scenes of works even become key factors which enhance atmosphere and strengthen plots, these scenes can not make people (especially non-local people of Zhuhai) have direct association with Zhuhai at once. The reason for this is that these scenes do not reflect specialty of sceneries in Zhuhai. On the contrary, it is easy to find such scenes in other cities. Thus, they can not propagate urban image of Zhuhai effectively.

3) Film and television works that are shot in Zhuhai and can reflect local stories of this city can be divided into two kinds, i.e., literary film and television programs and documentary film and television works.

First of all, film and television programs can be classified into two types. The first type tells enterprising and love stories about external entrepreneurs who went to Zhuhai after Reform and Opening-up, and the other type are film and television works narrating local historical stories and tales of Zhuhai. Themes, both themes and characters of these film and television works have relationship with Zhuhai. The former kind is represented by the film Sky People which is recomposed according to the Zhuhai writer Bei Pei's novel We Are Sky People wining Hundred Flowers Awards in China. The representative of the latter type is Zhuhai Fishing Girl which is recomposed in accordance with local myths and legends of Zhuhai and describes the reason why the city is named Zhuhai, i.e., a pearl on the head of Chang'e a goddess in the moon drops into South China Seaso that the city is named 'Zhuhai' (the sea covered with pearl-like islands).

Though themes and characters of these works are related to Zhuhai, it is rather difficult for scenes in these films to make the audience associate them with Zhuhai. For example, although the film Sky People was shot in Zhuhai, its scenes mainly include International Science and Technology building and Lovers' Road in Zhuhai. Such scenes do not have strong regional characteristics; or they do not show regional elegant demeanor obviously when they are expressed by shots, though scenes are representative buildings in Zhuhai. Consequently, this kind of film and television works cannot propagate urban image of Zhuhai effectively. Although the film Sky People was a key support project of cultural competitive products in Zhuhai in 2009, acted as a great gift for the $30^{\text {th }}$ anniversary after Zhuhai Special Economic Zone was established and was chosen in Venice International Film Festival, it had weak influence. In detail, it only achieved RMB 1,000 box office during the first two days after its first run, just as related observers said that 'there was nothing the worst but something worse'. Film language in this movie is international and endowed with artistic sentiment of European style. Nevertheless, these features dilute regional characteristics of Zhuhai unconsciously. Themes and characters of the film Zhuhai Fishing Girl reflecting historical stories and tales of Zhuhai accord with the purpose of Zhuhai's urban image, but scenes of this kind of film and television works only focus on some villages with ancient models and some natural sceneries of Zhuhai. However, these villages and natural sceneries fail to show special costumes of Zhuhai effectively.

Documentary film and television programs specifically introduce natural sceneries and situations about historical development of Zhuhai. This kind of documentaries has some effects on urban image communication of Zhuhai but does not hold much influence. The main reason for this is that such documentaries do not have much story narration about Zhuhai. For instance, One Day at Yuhu Lake discusses problems about ecological protection and water conservancy application of Gaozhou Reservoir in Zhuhai and the content it conveys is an issue existing all over the world, so the documentary cannot make people feel abundant and unique humanistic color. Thus, this film's propagation about urban image of Zhuhai is not effective either.

4) There are numerous works which are shot in Zhuhai but do not reflect local history and life stories of Zhuhai. Places where scenes of these film and television programs are shot cannot easily make people associate them with sceneries of Zhuhai. In addition, an increasing number of films are shot in Zhongshan a city which is neighboring to Zhuhai and only some supplemented shots are finished in Zhuhai.

\section{Discussion}

In accordance with foregoing analyses of film and television works that have been shot in Zhuhai in recent twenty years, a number of works shot in this city neither show unique urban image of Zhuhai effectively nor propagate urban image of Zhuhai efficiently. Although Zhuhai is honored as a famous tourist city where there is 
blue sea and sky, pretty landscapes and graceful sceneries, lots of tourists are attracted to travel in this city and many scenic spots of Zhuhai are places where films and television plays have their framing and are shot, urban image of Zhuhai is not propagated effectively because of these film and television works. In the era when a lot of Chinese cities compete with one another to develop tourist resources, it is no doubt that this phenomenon is a pity and even a crisis for urban development of Zhuhai.

Owning a number of tourist resources and places where scenes are shot, Zhuhai should relate them with its urban image communicate closely in order to achieve greater values in use. According to examples about some Chinese cities who have used film and television works to achieved effective urban image communicate in recent years, it can be found that investigations which are combined with current situations of Zhuhai can offer us some enlightenment

\subsection{Film and Television Works and Urban Image Molding}

Urban image is constructed. To a large extent, urban image is the result of imagination, because human beings are social animals who use cultural symbols for reflection, and the majority of cities they feel are gradually formed by medium symbols. These cultural symbols are integrated with people's finite practical experience, viewpoints and consciousness to form collective imagination of a city, namely, urban image.

It was believed by Stuart Hall, a British cultural study scholar, that object itself has no significance, which is merely the result of operating language and other cultural symbols, making it a process of constructing. Hall named this process "representation" and deemed that elements included in representation include not only some real and false objects, but also the original concepts and viewpoints of the subject, as well as such cultural symbols as language. Film and television works are a kind of representation. Rather than indiscriminately copying the reality, representation mixes reality and imagination together, which is under the influence of original viewpoints. Skills and modes of shooting films also play a decisive role in the generation of significance.

The representation of Zhuhai by film and television works is really not Zhuhai in the real sense. Since Zhuhai represented by these works will inevitably include people's imagination and be influenced by the operating mode of cultural symbols. Different modes of shooting a film and television work will have various influences on the representation of the framing sites. Cassirer, a German philosopher, once said in his work An Essay on Man: An Introduction to a Philosophy of Human Culture that "A symbol has no actual existence as a part of the physical world; it has a "meaning"" (Cassirer, 1944). The creation and shooting of film and television works provide new significance and colors to the urban image of Zhuhai.

Many cities often become well-known to us within a short period of time because of a film or a TV play, for example, Let the Bullets Fly in which Jiangwen played the leading role, boosted tourists visiting Kaiping Watchtowers in Jiangmen, Guangdong by four times within one year after it was released; the TV play One Meter Sunlight let many audiences' thoughts fly to Lijiang, Yunnan; the film The Grand Canal refreshed people's memories of Suzhou; Zhang Yimou's work Raise the Red Lantern was shot in Qiao's grand courtyard in Taiyuan, Shanxi in 1990. The crew contributed some money to renovate the courtyard once before shooting the film. In all aspects, this film presented the architectural style and features of Qiao's grand courtyard. Therefore, although only a line of small characters that said "framed and shot in Qiao's grand courtyard" in tail leader, the number of tourists visiting Qiao's grand courtyard reached 150,000 in 1991 after the film won an award in Berlin International Film Festival, ticket sales reached 200,000 RMB, which was nearly twice of that figure in 1989. During this period, many foreigners were so deeply attracted by it that they disregarded the trouble of traveling a long distance.

Why some films can enhance the utilization rate of local tourism resources within such a short period of time? The main cause is that this kind of films highlights the peculiar humanity and customs of the framing site in an artistic way and endows the locality with new cultural significance. While presenting a moving plot to the audiences, the TV play One Meter Sunlight also highlighted the local customs, practices and architectural style and features of Lijiang, Yunnan. As a result, many audiences formed a deep longing for Lijiang, Yunnan, and even some students strived to be admitted by universities in Lijiang after watching the TV play.

Due to the accelerated urbanization in China, many cities often bear modernized architectures in the industrialized society, and consequently, they seem to be highly similar and less distinctive. However, film and television works can represent and construct urban features in an unconventional and effective way, and highlight the style, nature and emotional appeal of the framing cities. What audiences see in film and television works is no longer monotonous frames of cities, but emotional and energetic faces. In the meanwhile, these faces also reinforce the expression of these film and television works. 


\subsection{Adequate Film and Television Shooting Resources in Zhuhai}

For a long time, the blue sky, white cloud, birds' twitter and fragrance of flowers in Zhuhai have attracted tourists from all over China. Furthermore, Zhuhai is also endowed with special attractiveness because it is near to Macao, which is developed in the gaming industry and is known as one of the three gambling towns in the world. However, since Macao is crowded with residences and people, Zhuhai is also regarded as the "backyard garden" of Macao with its superior natural environment and beautiful scenery.

Not only is Zhuhai a tourist attraction with beautiful scenery and pleasant weather, but also it is a city rich in cultural deposits. However, since Zhuhai was established not long ago, its previous historical rudiment seems to be rarely known by people. Zhuhai plays such an important role in the modern history of China that it is deemed as a contact point connecting the feudal era and the modern times of China.

In the late Qing Dynasty, Zhuhai was quite rich and populous, which led to the rise of re-education. Many old-style private schools were built in Zhuhai, and Fengshan Academy and Fengchi Academy were the relatively famous ones. Besides, Zhuhai is geographically close to Macao and Hong Kong, and Guangdong has been an important treaty port on the sea since ancient times, which enabled the transmission of Western learning atmosphere very early. Therefore, Zhuhai witnessed the rise of many new ideas in modern times. Such eminent figures in history as Sun Yat-sen, Tang Shaoyi and Su Manshu were born in Zhuhai. They have extremely profound influence on the modern history of China. However, there are few comments regarding the part of modern history happened in Zhuhai. Films and television works shot in Zhuhai should attach much importance to the historical resource and reveal Zhuhai's charms as a propitious place with great people.

In terms of some cultural resources in the modern times, the historic site Yilan Pavilion of a calligrapher named Baojun in the Qing Dynasty is also in Zhuhai. Zhuhai repaired this historic site again in 2012 and built Shixi Yilan Pavilion Garden, which further enriched Zhuhai's landscape of historic figures and cultural heritage. Apart from the rich historical and cultural resources in the modern times, Zhuhai is also in the possession of historic sites that are more distant from us. There are many villages in Zhuhai, for example, Cuiwei Village, Nanping Village and Beishan Village in Xiangzhou District, they all appeared in the Song Dynasty. Many buildings in the villages are of extremely high historical value and have reached a highly advanced level in architecture.

Apart from these ancient villages in Xiangzhou District, Dongmen District is a place gathering ancient buildings, such as Jiexia Village, Wangshan Village, Mutouchong Village and Huitong Village. Up till 2009, Jiexia Village, Huitong Village and Wangshan Village in Zhuhai have been listed as "provincial-level ancient villages". As time goes by, however, these ancient buildings have been gradually damaged under the erosion of wind and rains, some villagers fail to cherish and protect these villages and lease them randomly, and many new buildings have showed up. All of these put an end of these ancient villages step by step.

Some directors commented that some ancient villages in Zhuhai could be used to frame and shoot films. In this way, film and TV media, and the protection of ancient buildings can bring out the best in each other. Film and TV media can publicize the style and features of some old buildings of Zhuhai and bring the locality rich return through tourism, and in the meanwhile, the repair and protection of ancient buildings can provide more resources to shoot film and television works.

Other than the natural environment and historical and humanistic resources, Zhuhai is also a city with the largest number of undergraduates in Guangdong Province apart from Guangzhou. The total number of graduates reaches 100,000 , and many colleges and universities in Zhuhai have opened up film and television and art major. This offers adequate and superior human resource to the development of film and television producing industry in Zhuhai. In addition, industrial centers related with film and television production as South Digital Entertainment Public Service Center and South Screen Culture Industrial Base have been established in Zhuhai. "Zhuhai is absolutely capable of becoming a Chinese film and television industrial base and one of the three legs of a tripod with Hengdian and Huairou." (Xu, 2011)

Guangdong Zhuhai South Screen Culture Industry Company had an opening ceremony in May 2011. Ever since then, Zhuhai south screen culture industrial base project, which includes three aspects as film and television shooting and production, theme travel and culture creativity, has been implemented. This project was listed into ten projects of Guangdong Planning Outlines of Constructing Strong Cultural Province. Afterwards, it was listed into key projects of cultural construction in the " $12{ }^{\text {th }}$ Five-Year Plan" in Guangdong and Zhuhai, and becomes a leading enterprise in the tourism culture industry in Zhuhai.

\subsection{The Utilization of Industrial Resources in Zhuhai Screen Culture}

Zhuhai enjoys many advantages in tourist environment, human resource and industrial construction, which are 
conducive to Zhuhai's development of urban culture industry based on the sally port of film and television industry. If the tourist industry and film and television industry of Zhuhai are integrated together, huge effect will show up.

Ever since 1995, two-day weekend has come into force in China. The vacation time was adjusted again in 1999 by adding the days off work to 114 days a day for urban residents, which means they spend one third of their life in a leisure state. This indirectly stimulates the development of our tourist industry. Zhuhai is a tourist city, so if the tourist industry and film and television industry are integrated together in Zhuhai, the optimization of its industrial structure will be benefited.

First of all, film and television works are a kind of art which has aesthetic effect. Superficially, beauty contains no utilitarian purposes, but in the meanwhile, it accords with utilitarian purposes, because beauty lives up to the standard of judging every beautiful thing. Some film and television works represent and construct urban image very skillfully, making it an effective way of improving urban image and competitiveness.

Many cities have their own advertising video, which is a direct and utilitarian means of publicity. These advertising videos directly demonstrate a city's local customs, practices and geographical conditions, which is highly conducive to reinforcing urban competitiveness, attracting foreign businesses and investment, and absorbing talents. There's no doubt that city advertising video is important, but its utilitarian purpose far exceeds its aesthetic consideration. Besides, nowadays, as commercial advertisements are overwhelming, short city advertising videos rarely leave a deep impression on people. However, the shooting of literary film and television works can meet this requirement, because these works seem to contain no direct purposes of publicizing the city, but its literary means of representation further interiorizes urban image.

It is believed by early bullet theory that communication can hit the target and reach the ideal effect just like a bullet. However, it is held by some people that communication does not reach the effect like a bullet, but exerts a subtle influence on one's character. Bullet theory neglects the audiences' viewpoints and acceptance. As a deliberate means of publicity, city advertising video will undoubtedly lead to audiences' conflict psychology. While film and television works can easily eliminate audiences' such psychology and reach the expected purposes.

It is proved by facts that skillful implication and unconscious influence are more effective than direct persuasion. Urban image can be embedded into film and television works through various modes. "A careless actor's line and a flash shot can become the medium through which a city shows up; such communication is so natural, cordial and vivid that it is no longer hollow, but associated together with specific figures and incidents, which endows the city various characters."(Chen \& Yuan, 2011)

Zhuhai and film and television works can be "associated together" through many modes. For example, shooting film and television works regarding the history and reality of Zhuhai by directly taking Zhuhai as the theme; or shooting stories happened in Zhuhai; framing certain landscapes in Zhuhai to shoot film and television works. Some cities in China have works which take themselves as the theme, for example, Blooming of the Lotus in Chengdu, the shooting of this kind of film and television works is a self-promotion of cities. Due to vivid plots, this kind of works leave a deeper impression on people than city advertising videos and can be spread more extensively. However, more cities show up as a site of framing stories in film and television works, and if relevant departments take the initiative to seize the opportunity to publicize the city, it will further improve the urban image of Zhuhai and enhance tourist revenue. It is through such publicity that many cities acquire rich return, and such instances are too numerous to list. For example, National Granary and Time Passes Like Flowing Water which were shot in Wuzhen, Zhejiang, Qiao's Grand Courtyard which was shot in Qi County, Shanxi, and Five Golden Flowers which was shot in Dali, Yunnan.

In these film and television works, the representation of urban image and regional land is no longer hollow, empty, stiff or dull, but vivid, natural and alive. For instance, the representation of Tibetan sceneries in film Red River Valley: instead of didactic communication, it naturally brings the glamorous sceneries of Tibet into the film through heroic acts. In this way, while the audiences are moved by the lofty and heroic plots, they also have a taste of the charm of Tibetan sceneries. In this film, the reveal of the beautiful sceneries in Tibet is natural, without any boringness of ads promotion.

In concrete works, Zhuhai's image can be naturally embedded in works through actor's lines, film and television themes, landmark buildings or sculptures, and folk customs. Certainly, the representation of individual scenic spot or regional diet in film and television works reaches finite effect in cultural communication, if the overall cultural implication of Zhuhai can be highlighted in works, the urban image of Zhuhai can be communicated more effectively. After the communication of urban image through film and television works, it can also be 
communicated online or through interpersonal relations. Option leader will arise in this process, which will lead to better and more extensive communication effect.

The publicity of Zhuhai's urban image in film and television works need relevant departments' conscious and initiative movement. Although many film and television works are shot in Zhuhai every year, producers of these films are not obligated or responsible for publicizing Zhuhai's urban image. Framing sites and the selection of shooting sites in these works depend on the demands of theme. Generally speaking, the main purpose of film and television works is also not to publicize a city. Although the shooting sites will be indicated in film and television works, they are not deemed as the key point. Therefore, relevant departments should take the initiative to communicate with the producers of these works, and the media should also follow up and cover the shooting of these works in time. In this way, urban image can be publicized on the one hand, and on the other hand, film and television works can become more popular, which reaches win-win effect.

\section{References}

Cassirer, E. (1944). An Essay on Man: An Introduction to a Philosophy of Human Culture. Yale University Press.

Chen, B., \& Yuan, J. (2011). On the Study of Urban Image Communication in Film and Television Works. Press Outpost, (6), 56-57.

Li, X. ( 2012). Utilizing Screen Culture Actively to Accelerate Urban Image Construction and Communication of Liaoning. Reform \& Openning, (22), 180-181.

Li, Z., \& Xue, Y. (2006). Screen Culture and Urban Image Communication. Film Review, (20), 19-21.

Liu, W., \& Xu. M. (2011). Using Advertisements Embedded in Film and Television to Build Urban Image of Yongzhou. Journal of Hunan University of Science and Engineering, (4), 206-208.

Tong, L., \&Zhang, R. (2012). Research on Communication of Modern Urban Image by Films. Art Engineering and Creative Industry International Academic Conference Proceedings in 2012, 17.

Wang, X., Li, Z., \& Xu, D. (2011). Analyzing the Effect of TV Series Noble Family on City Image by Image Reading Method. Journal of Qiqihar University, (3), 156-158.

$\mathrm{Xu}, \mathrm{H}$. (2011). Film and Television Industry-Sally Port in Zhuhai Cultural Industry's Great-leap-forward Development. Zhuhai Administration School Academic Journal of CPC Zhuhai Municipal Party Committee, (6), 49-64.

Zhu, H., \& Wang, Y. (2010). Urban Image Communication of TV Plays and Competition of Culture Soft Power. Journal of Jiangsu University, (2), 11-14.

\section{Copyrights}

Copyright for this article is retained by the author(s), with first publication rights granted to the journal.

This is an open-access article distributed under the terms and conditions of the Creative Commons Attribution license (http://creativecommons.org/licenses/by/3.0/). 